5 Gourley 1 M. Paroxysmal torticollis in infancy. Can Med Assoc J 1971; 105: 504-5.

- Dunn D W, Snyder C. Benign paroxysmal vertigo of childhood. Am J Dis Child 1976; 130: 1099-100.

7 Deonna $T$. Le problème neurologique de la migraine accompagnée chez l'enfant. Pediatrie 1977; 32: 119-27.
- Fenichel G M. Migraine as a cause of benign paroxysmal vertigo in childhood. J Pediatr $1967 ; 71: 114-5$.

Correspondence to $\operatorname{Dr} T$ Deonna, Service de Pediatrie, CHUV, 1011 Lausanne, Switzerland.

Received 23 June 1981

\title{
Postural deformities in congenital nephrotic syndrome
}

\author{
G MORGAN, R J POSTLETHWAITE, M LENDON, I B HOUSTON, AND J M SAVAGE
}

Royal Manchester Children's Hospital, Manchester

SUMMARY Six successive cases of congenital nephrotic syndrome are described. Each one showed flexion deformities of the knees and hips, widely open anterior and posterior fontanelles, and wide separation of the skull sutures. These abnormalities were present not only in cases in which the renal histology was of the microcystic Finnish type of congenital nephrotic syndrome, but also in those in which the histological picture was one of the variants associated with congenital nephrotic syndrome. It is suggested that such abnormalities are postural deformities, possibly produced by the large placenta.

In congenital nephrotic syndrome (CNS) heavy proteinuria and hypoalbuminaemia are present at birth. Affected babies may be hydropic, but more commonly oedema only develops in the first few days of life. Occasionally, the appearance of oedema may be delayed for weeks or months. CNS is generally familial and idiopathic, but may be secondary either to infection or to renal vein thrombosis although this is rare. ${ }^{1}$

The Finnish type of CNS is inherited as an autosomal recessive. ${ }^{1}$ In this syndrome the placenta is always large, generally at least $25 \%$ of the birthweight. Preterm delivery and birth asphyxia are common, and the baby is usually of low birthweight. Typically, the baby has a small, low-bridged nose, the anterior and posterior fontanelles are widely open, and the skull sutures widely separated. Calcaneovalgus deformities of the ankles are common. ${ }^{1}$ Other histological types of congenital and familial nephrotic syndrome occur. The two most common variants are diffuse mesangial sclerosis and focal glomerular sclerosis. ${ }^{1}$

The 6 patients with CNS described in this report showed all these abnormalities and they had other skeletal and articular abnormalities too. Two of them did not have the Finnish type of CNS.

\section{Case reports}

Details of the 6 cases are given in the Table. In 4 cases the placental weight was recorded and was between 40 and $52 \%$ of the birthweight, in a fifth case the placenta had been noted to be 'very large'. Each baby developed oedema within one week of birth. The diagnosis of nephrotic syndrome was confirmed by demonstrating hypoalbuminaemia (serum albumin $8-20 \mathrm{~g} / \mathrm{l}$ ) and heavy proteinuria (urine protein $80-180 \mathrm{mg} / \mathrm{h}$ per $\mathrm{m}^{2}$ ).

Large anterior and posterior fontanelles with widely separated sutures were present in all 6 patients, as were flexion deformities of the hips and knees

Table Summary of patients

\begin{tabular}{|c|c|c|c|c|c|c|}
\hline & \multicolumn{6}{|l|}{ Case } \\
\hline & 1 & 2 & 3 & 4 & 5 & 6 \\
\hline Histological type & Finnish & Finnish & Finnish & Finnish & $\begin{array}{l}\text { Diffuse } \\
\text { mesangial } \\
\text { sclerosis }\end{array}$ & $\begin{array}{l}\text { Focal } \\
\text { segmental } \\
\text { sclerosis }\end{array}$ \\
\hline \multicolumn{7}{|l|}{ Placental weight } \\
\hline $\begin{array}{l}\text { (\% of birthweight) } \\
\text { Large fontanelles and wide sutures }\end{array}$ & $\begin{array}{r}47 \\
+\end{array}$ & $\begin{array}{l}40 \\
+\end{array}$ & $\begin{array}{l}\text { Not recorded } \\
+\end{array}$ & $\begin{array}{l}\text { Very large } \\
+\end{array}$ & $\begin{array}{l}\text { Not recorded } \\
+\end{array}$ & $\begin{array}{c}52 \\
+\end{array}$ \\
\hline Talipes calcaneovalgus & + & + & + & - & - & - \\
\hline \multicolumn{7}{|l|}{ Flexion deformities: } \\
\hline Hips & + & + & + & + & + & + \\
\hline Knees & + & + & + & + & + & + \\
\hline Elbows & + & + & - & + & + & + \\
\hline Single palmar crease & + & - & - & - & - & + \\
\hline High arched palate & + & - & - & - & + & + \\
\hline Arachnodactyly & + & - & - & - & + & + \\
\hline
\end{tabular}


(Fig. 1). Flexion deformities of the elbows were present in 5 of them. Talipes calcaneovalgus was present in 3 patients, all of whom had Finnish type CNS. Three babies, one with Finnish type CNS, had high arched palates and arachnodactyly, 2 of whom also had single palmar creases and ulnar deviation of the wrist (Fig. 2).

The 4 cases with Finnish type CNS died before age 3 months of infections or electrolyte problems associated with treatment with diuretics. Both patients with the other variants are alive at age 4 years. Case 5 (diffuse mesangial sclerosis) has heavy proteinuria, oedema, and a reduced creatinine clearance $\left(20 \mathrm{ml} / \mathrm{min}\right.$ per $\left.\mathrm{m}^{2}\right)$ and Case 6 (focal segmental sclerosis) has normal renal function (creatinine clearance $90 \mathrm{ml} / \mathrm{min}$ per $\mathrm{m}^{2}$ ) but gross disabling oedema. In both these surviving infants the fontanelles closed normally and the joint abnormalities resolved without any specific treatment, despite the persistence in Case 6 of generalised muscle wasting and gross hypotonia.

\section{Histology}

Cases 1-4. At necropsy the skeletal and articular deformities were confirmed, but no structural joint abnormality could be seen. The kidneys showed numerous tubular cysts at the cortico-medullary junction, compatible with the Finnish type of CNS.

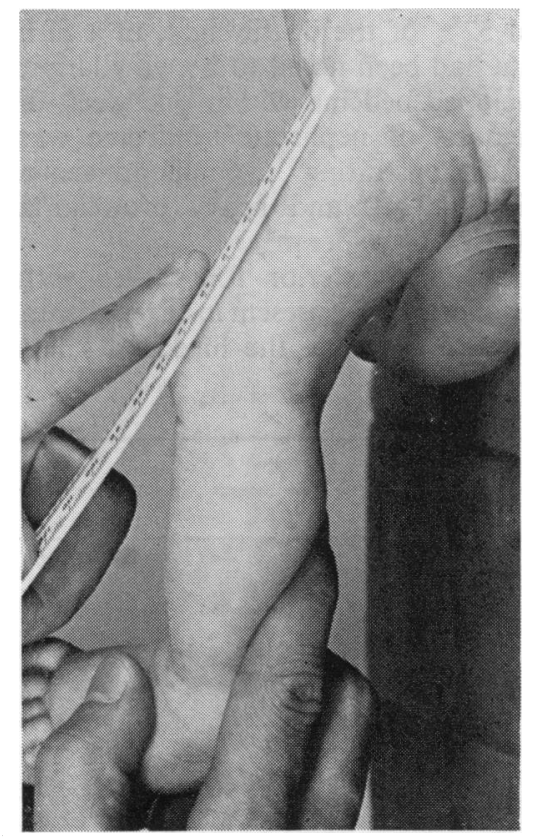

Fig. 1 Typical knee deformity. Limitation of extension of the knee is shown.

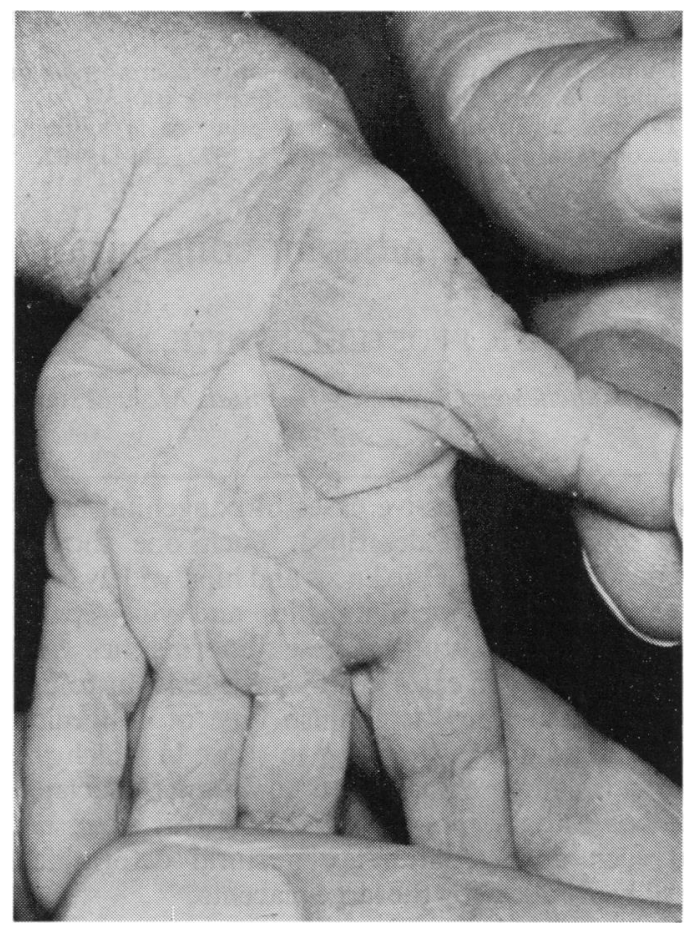

Fig. 2 Ulnar deviation of the wrist which is easily correctable.

Case 5. Two percutaneous renal biopsies were performed. The first, at age 1 year, contained $39 \stackrel{\circ}{\circ}$ glomeruli. Nine of these were globally sclerosed $\stackrel{\varnothing}{\circ}$ while the others showed varying degrees of mesangial $\overrightarrow{\overrightarrow{0}}$ proliferation. There was mild tubular dilatation but 3 no cysts were seen. The second biopsy, at age $2 \frac{1}{2} \vec{F}$ years, showed pronounced deterioration with all 23 glomeruli showing either mesangial sclerosis or proliferation, and with considerable tubular atrophy, interstitial inflammation, and vascular change.

Case 6. An open biopsy was performed at age 9 months. Unfortunately this only contained 25 glomeruli from the superficial cortex. Nine of these $\frac{9}{5}$ showed global or segmental sclerosis. There was mild $\underset{O}{\square}$ tubular atrophy. No cysts were seen, but since the cortico-medullary junction was not included it was $\widetilde{N}$ not possible categorically to exclude the Finnish $N$ type of CNS. The mesangial proliferation however, $\mathrm{N}$ suggested focal segmental sclerosis.

\section{Discussion}

Six successive patients with CNS who have presented to this department have all shown large fontanelles and widely separated skull sutures, but all have also 
shown flexion deformities of the hips and knees; the elbows were also affected in 5 patients. Three of the 4 cases with Finnish type CNS had talipes calcaneovalgus. Additional features were variably present; these were ulnar deviation of the wrist, high arched palate, single palmar crease, and probable arachnodactyly.

The calcaneovalgus deformity in the Finnish type of CNS is generally attributed to muscle weakness ${ }^{1}$ and the widely open fontanelles and separated sutures attributed to 'delayed calcification' with no more specific explanation. ${ }^{1}$ Muscle weakness could clearly also cause the other joint problems. As both skull anomalies and flexion deformities were present in both cases of the Finnish type of CNS and those with other histological appearances, they are not a specific association of Finnish type CNS but must arise as a consequence of having nephrotic syndrome in utero.

The limb deformities are reminiscent of the deformities observed in Potter's syndrome. In Potter's syndrome the deformities arise as a result of limitation of movement and extrinsic pressure in utero due to the severe oligohydramnios; similar postural deformities have been described in bilateral renal hypoplasia, multicystic kidneys, urethral atresia, and urethral valves. ${ }^{2}$ The absence of structural changes in the joints at necropsy and the spontaneous correction of the deformities in the 2 children who survived the neonatal period would support the contention that the deformities are postural in origin.

In CNS Finnish type amniotic fluid $\alpha$-fetoprotein has been shown to be regularly increased during the second trimester, and it has been shown that this high level of amniotic fluid $\alpha$-fetoprotein is accompanied by fetal proteinuria. ${ }^{3}$ This fetal proteinuria could produce fetal oliguria and reduce the volume of amniotic fluid. We have no information about the volume of amniotic fluid in our patients.

An equally effective limitation of intrauterine movement could be produced by the very large placenta which is present in CNS. In the 3 cases in which the placental weight was available it was $40-52 \%$ of the birthweight.

In a recent report, the presence of parietal craniotabes in the newborn was related to early engagement of the fetal head. ${ }^{4}$ Two of the 10 infants had widening of the anterior and posterior fontanelles and of the sagittal suture, to such an alarming extent that investigations to exclude hydrocephalus were carried out $;^{4}$ the skull anomalies in all 6 of our patients were equally striking. Attention was also drawn to a previous report of 55 term Chinese babies with unusually wide sagittal sutures which had returned to normal in 9-11 weeks ${ }^{5}$ and it was suggested that the aetiology of the widened sutures might be similar to that of the parietal craniotabes. ${ }^{5}$ The large placenta, either directly or by producing early engagement of the fetal head, could explain the skull abnormalities of CNS and would explain why they resolve in surviving children.

Amniocentesis in rats at a certain stage in gestation leads to mid-line cleft palate ${ }^{6}$ and the higharched palate observed in 3 of our patients may represent a further effect of extrinsic pressure.

The placentas of our patients were not available for histological examination, but there is evidence that the large size is mainly due to oedema. ${ }^{7} \mathrm{~A}$ few reports have indicated that the fetal-placental ratio is normal in the second trimester ${ }^{8}$ although electron microscopical changes in the kidney and proteinuria are present by this time. ${ }^{38}$ The placental changes would seem therefore, to be secondary to the fetal disease and probably result from the low oncotic pressure in utero. A large placenta would therefore, be expected to occur in all types of CNS.

No radiological assessment of the arachnodactyly was made and the accuracy of this clinical assessment is uncertain. A possible association of this feature with CNS requires adequate assessment. A single palmar crease was present in 2 children, while the occurrence in unselected newborn infants is $5.3 \%{ }^{9}$ Even with such a small sample, this probably represents a true association.

The limb deformities in CNS are more widespread than is usually described, often affecting knees, hips, wrists, and elbows, in addition to the ankles. These deformities have the characteristics of postural deformities, probably produced by the large placenta; oligohydramnios and hypotonia may be additional contributory factors. Skull abnormalities were universally present and these, and the high arched palates which were variably present, may also arise as a result of extrinsic pressure or limitation of movement. These limb deformities and abnormalities of the skull are non-specific features of CNS and a neonate with CNS and these typical features cannot be assumed to have the Finnish type of CNS.

We thank Miss J E Brooks for secretarial help.

\section{References}

1 Hallman N, Rapola J. Congenital nephrotic syndrome. In: Edelmann $\mathrm{C} \mathrm{M}, \mathrm{Jr}$, ed. Pediatric kidney disease. Boston: Little Brown, 1978: 711-8.

2 Dunn P M. Congenital postural deformities. Br Med Bull $1976 ; 32: 71-6$.

3 Thom H, Johnstone F D, Gibson J I, Scott G B, Noble D W. Fetal proteinuria in diagnosis of congenital nephrosis detected by raised alpha-fetoprotein in maternal serum. Br Med J 1977; i : 16-8.

4 Graham J M, Jr, Smith D W. Parietal craniotabes in the neonate; its origin and significance. J Pediatr 1979; 91 : 114-6. 
5 Tan K-L. Wide sutures and large fontanelles in the newborn. Am J Dis Child 1976; 130: 386-90.

B Poswillo D. The aetiology and surgery of cleft palate with micrognathia. Ann $R$ Coll Surg Engl 1968; 43: 61-88.

7 Kouvalainen K, Hjelt L, Hallman N. Placenta in congenital nephrotic syndrome. Ann Paediatr Fenn 1962; 8: 181-7.

8 Seppälä M, Rapola J, Huttunen N P, Aula P, Karjalainen $O$, Ruoslahti E. Congenital nephrotic syndrome: prenatal diagnosis and genetic counselling by estimation of amnio- tic fluid and maternal serum alpha-fetoprotein. Lancet 1976; ii: $123-5$.

9 Davies P A, Smallpiece V. The single transverse palmar crease in infants and children. Dev Med Child Neurol $1963 ; 5: 491-6$.

Correspondence to Dr R J Postlethwaite, Royal Manchester Children's Hospital, Pendlebury, Manchester M27 1HA.

Received 21 May 1981

\title{
Down's/Turner's mosaicism
}

\section{Double aneuploidy as a rare cause of missed prenatal diagnosis of chromosomal abnormality}

\author{
R MACFAUL, T TURNER, AND M K MASON \\ Pinderfields General Hospital, Wakefield, Hull Royal Infirmary, and St James's University Hospital, Leeds
}

\begin{abstract}
SUMmARY Two babies with Down's/Turner's mosaic karyotype are reported. In each, because of advanced maternal age, chromosomal analysis had been carried out on the fluid obtained by amniocentesis in early pregnancy. Only the $46, X+21$ cell line grew in the specimens and the extra 21 chromosome was wrongly identified as a $Y$ chromosome, so that the fetus was thought to have a normal male karyotype, 46,XY. At birth both babies were phenotypically female with features predominantly of Down's syndrome and the correct karyotype was then identified. Twenty cases of this rare chromosomal abnormality are reviewed and one other living child who had been similarly wrongly diagnosed is reported.
\end{abstract}

Down's/Turner's mosaic is a rare chromosomal abnormality, occurring in about 1 in 2000000 births. ${ }^{1}$ We report 2 babies born with this disorder in each of whom chromosomal analysis of amniotic fluid had mistakenly identified the fetus as a normal male.

\section{Case 1}

Amniocentesis was performed at 17 weeks' gestation at the mother's request in view of her age. This was the third pregnancy of a 36-year-old mother but the first child of her 65-year-old second husband. The karyotype of the fetus was reported as 46,XY. At 38 weeks' gestation a girl weighing $2590 \mathrm{~g}$ was born normally. The infant had the facial appearance of a Down's syndrome; she was markedly hypotonic with a low hairline, and had pronounced webbing of the neck. The heart was normal. Karyotype was $46, X+21 / 47 X X+21$. The $46 X+21$ was present in $12 \%$ of the cultured cells. At age 11 months she had the appearance typical of Down's syndrome together with some webbing of the neck. Develop ment was delayed at a 7-month level and she was. growing in length along the 3 rd centile.

\section{Case 2}

A 38-year-old mother in her second pregnancy requested amniocentesis at 15 weeks. The amniotic fluid karyotype was thought to be $46, X Y$. A girl weighing $1750 \mathrm{~g}$ was delivered at 36 weeks' gestation by caesarean section performed for intrauterine growth retardation. The infant had the facial appearance of Down's syndrome, a large clitoris, puffy hands and feet, and for a few days was cyanosed in air, and had a cardiac murmur. There was a single palmar crease and talipes on the right. She died from bronchopneumonia aged 15 weeks. The karyotype obtained in the neonatal period was $47, X$ iso $X+21 / 46, X+21$.

\section{Discussion}

In each instance the karyotype of the fetus after cell culture from amniotic fluid was thought to be $46, X Y$, because in each only the $46 X+21$ cell line had grown. The extra 21 chromosome was interpreted to be the $Y$ chromosome in a normal total of 46 chromosomes, as the appearance of a 21 chromosome is very similar in size and shape to the $Y$ chromosome. Chromosomal banding is not undertaken routinely in 